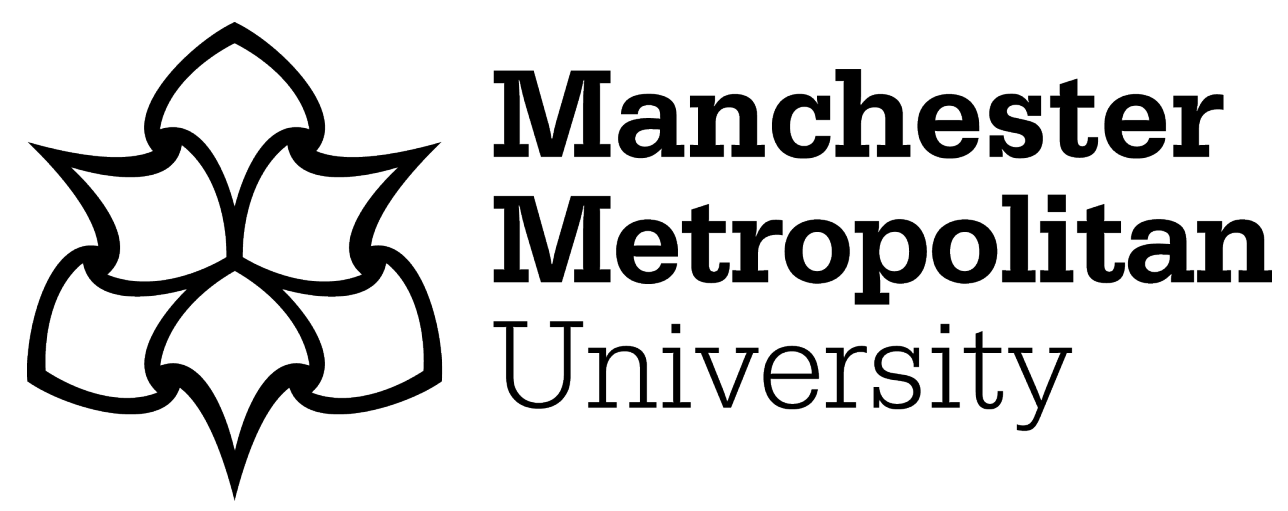

Bogdziewicz, M, Kelly, D, Thomas, PA, Lageard, JGA ORCID logoORCID: https://orcid.org/0000-0001-8971-0444 and Hacket-Pain, A (2020) Climate warming disrupts mast seeding and its fitness benefits in European beech. Nature Plants, 6. pp. 88-94. ISSN 2055-026X

Downloaded from: https://e-space.mmu.ac.uk/625340/

Version: Accepted Version

Publisher: Nature Research

DOI: https://doi.org/10.1038/s41477-020-0592-8

Please cite the published version 


\title{
Climate warming disrupts mast seeding and its fitness benefits in European beech
}

\author{
Michał Bogdziewicz $\mathbb{1}^{1 \star}$, Dave Kelly², Peter A. Thomas $\mathbb{D}^{3}$, Jonathan G. A. Lageard ${ }^{4}$ and \\ Andrew Hacket-Pain ${ }^{5}$
}

\begin{abstract}
Many plants benefit from synchronous year-to-year variation in seed production, called masting. Masting benefits plants because it increases the efficiency of pollination and satiates predators, which reduces seed loss. Here, using a 39-year-long dataset, we show that climate warming over recent decades has increased seed production of European beech but decreased the year-to-year variability of seed production and the reproductive synchrony among individuals. Consequently, the benefit that the plants gained from masting has declined. While climate warming was associated with increased reproductive effort, we demonstrate that less effective pollination and greater losses of seeds to predators offset any benefits to the plants. This shows that an apparently simple benefit of climate warming unravels because of complex ecological interactions. Our results indicate that in masting systems, the main beneficiaries of climate-driven increases in seed production are seed predators, not plants.
\end{abstract}

A nthropogenic environmental changes exert increasing pressure on forests worldwide ${ }^{1}$. Research on the effects of environmental change on trees has focused on the impacts on tree growth, carbon sequestration, mortality or phenology ${ }^{2-4}$. There have been few studies of the impacts of environmental change on the reproductive ecology of trees, yet long-term changes in reproduction determine the ability of trees to disperse to shifting habitats and recolonize sites after disturbance ${ }^{5}$. What is more, reproduction of trees is likely to be sensitive to climate change, especially in the case of mast seeding (or masting) species-that is, those that reproduce through spatially synchronous and temporally variable seed production-due to strong correlations of seed production with annual variation in weather ${ }^{6-8}$.

Many plant species, including most forest-forming tree species in temperate zones, reproduce through mast seeding ${ }^{9,10}$. While masting plants are expected to be sensitive to global change ${ }^{11-13}$, the direction of that change is a source of controversy. Predictions range from an increase, to a decrease, to an unchanged strength of masting (that is, interannual variability and synchrony) in response to climate change $\mathrm{e}^{11,14,15}$, depending on the sensitivity of masting to climate and associated resources. However, the strength of masting is crucial in terms of plant fitness and forest regeneration, since masting is a life history trade-off between missed reproductive opportunities in low seed years and enhanced pollination efficiency and decreased seed predation in mast years ${ }^{16-18}$. Studies that measure seed production, pollination efficiency and seed predation for long enough to capture potential change are key to understanding how anthropogenic climate change will affect plant reproduction and thus global vegetation dynamics but such studies are virtually nonexistent. Here, we report on a unique 39-yr study of 139 individuals of European beech (Fagus sylvatica) across 12 sites in England that documents how the success of this major European forest-forming tree species, including seed production, predispersal seed predation by Cydia fagiglandana (Lepidoptera) and pollination success, has changed throughout the last four decades.

Mast seeding enhances plant fitness through economies of scale that decrease the cost of reproduction per surviving offspring ${ }^{12,19}$. This mainly happens through two mechanisms. The first is that large and synchronized flowering effort enhances pollination success because pollination efficiency is increased when the density of flowers is high (density-dependent, pollination efficiency hypothesis) ${ }^{16,20,21}$. Second, masting decreases seed predation by starving predator populations in years of low seed production and then satiating them in high seed years (predator satiation hypothesis) ${ }^{22-24}$. Predator satiation is crucially dependent on the sequence of high and low years, whereas pollination efficiency is affected by the size, not sequence, of high flowering years ${ }^{25}$. Therefore, the effects of global change will act differently on these two economies of scale, depending on how it alters plant reproductive variability and reproductive synchrony. This, in turn, depends on the causal relationship between masting and weather cues. Notably, if plants respond to the temperature difference between the two previous summers, as suggested by the $\Delta T$ model, then masting should be relatively insensitive to increased mean temperatures (though sensitive to changes in temperature fluctuation $)^{14}$. By contrast, if seed production is driven by interactions between plant internal resource dynamics and weather cues, such as warm absolute temperatures, more frequent cueing will decrease synchrony among plants, reducing populationlevel year-to-year variation in seed crops $^{17,26}$. Similarly, according to the environmental stress hypothesis, resource-augmented plants should increase mean seed production and their reproduction should become less variable over time ${ }^{25,27}$. If global environmental change disrupts masting patterns, the long-term regeneration of masting plants may decrease at the same time as global warming requires increasingly rapid geographic range shifts to keep species within suitable climate zones $^{28,29}$.

'Department of Systematic Zoology, Faculty of Biology, Adam Mickiewicz University, Poznan, Poland. ${ }^{2}$ Centre for Integrative Ecology, School of Biological Sciences, University of Canterbury, Christchurch, New Zealand. ${ }^{3}$ School of Life Sciences, Keele University, Staffordshire, UK. ${ }^{4}$ Department of Natural Sciences, Manchester Metropolitan University, Manchester, UK. ${ }^{5}$ Department of Geography and Planning, School of Environmental Sciences, University of Liverpool, Liverpool, UK. *e-mail: michalbogdziewicz@gmail.com 

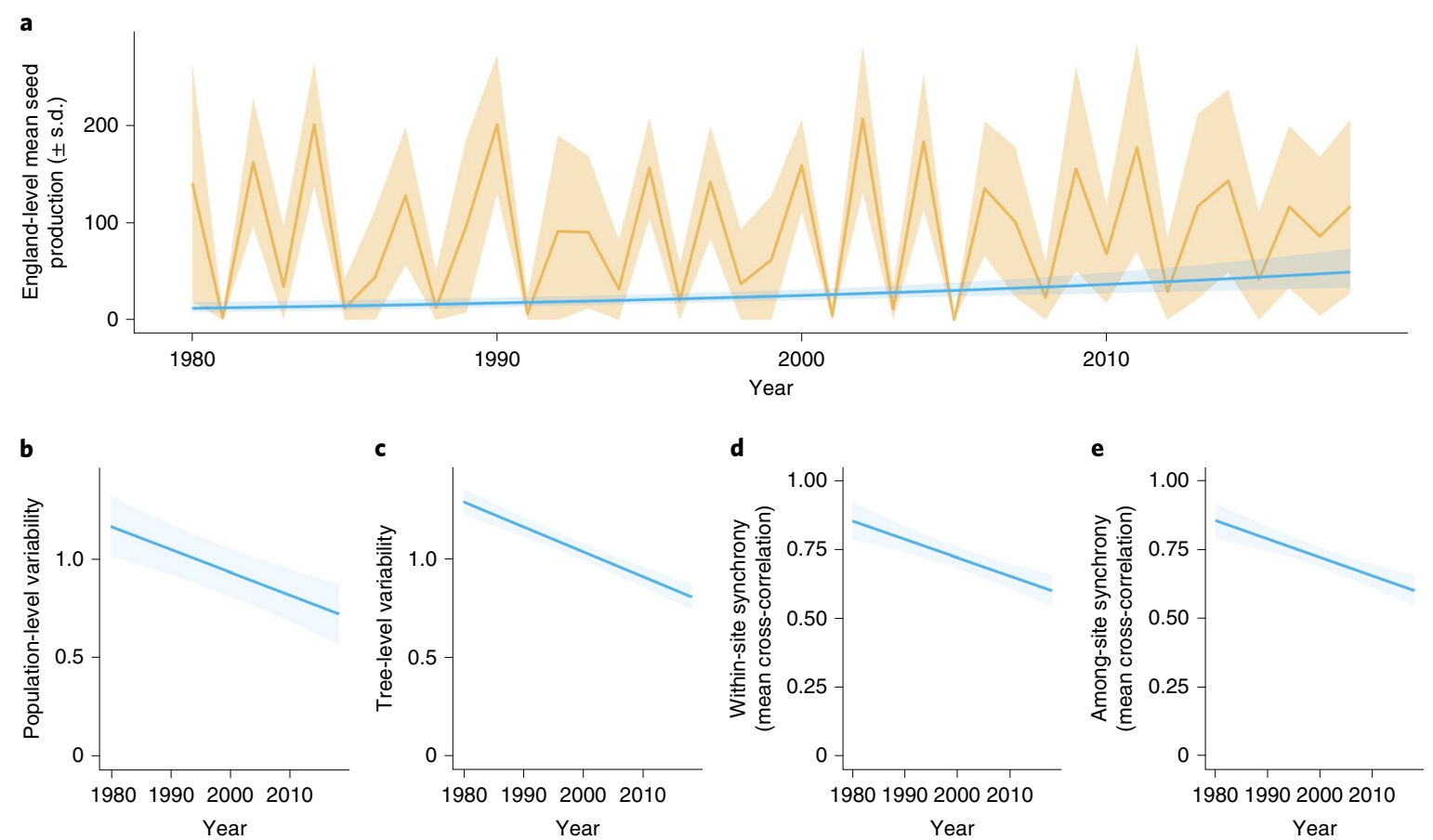

Fig. 1 | Temporal trends in European beech (F. sylvatica) seed production in England: population- and individual-level variability, and within- and amongsite synchrony of reproduction for 12 sites and 139 trees (1980-2018). a, Observed population-level seed production per year per 7-min search periods and fitted long-term mean. b-e, Significant fitted trends in temporal change in population-level CVp (b), mean individual CVi (c), synchrony among trees within a site (d) and synchrony among sites (e). Trends were calculated using GLMMs, with the site and trees as random intercepts and year as a fixed effect. Models also included an first-order autocorrelation structure. Shading around prediction lines indicates the $95 \%$ confidence intervals. See Methods for further details.

\section{Results}

Our 39-yr dataset of seed production in 139 European beech trees indicated that mean reproductive effort increased during the study period but mast seeding became progressively weaker (Fig. 1). Mean annual seed production per tree increased (Fig. 1a, $z=4.29, P<0.001$ ), while the probability of a tree having a year of zero seed production decreased over time $(z=-2.29, P=0.003)$. Accordingly, sliding window analysis indicated that interannual variation in reproduction measured by the coefficient of variation $(\mathrm{CV})^{30}$ decreased $40 \%$ at the population level $(\mathrm{CVp})$ from around 1.15 to 0.70 (Fig. $1 \mathrm{~b}, z=-4.93, P<0.001$ ) and at individual treelevel (CVi) from around 1.30 to 0.80 (Fig. 1 c, $z=-9.74, P<0.001$ ). Furthermore, synchrony, measured by mean cross-correlation of seed production among trees, also decreased by $30 \%$ from over 0.85 to around 0.60, both at the within-site level (Si) (Fig. 1d, $z=-4.66$, $P<0.001)$ and among-site level (Sp) (Fig. 1e, $z=-7.27, P<0.001$ ). Thus, population-level variation in seeding across years decreased because individual trees varied less from year-to year and trees were more poorly synchronized.

The analysis of abiotic drivers of seed production supported mathematical models of the role of environmental cues or vetoes in mast seeding, which predict that more frequent occurrence of weather cues for reproduction should result in a decrease in both variability and synchrony of seed crops ${ }^{17,26}$. In the case of European beech, seed production correlates positively with warm summer temperature 1 yr before seed dispersal (Supplementary Table 1), probably by promoting flower initiation ${ }^{8,31}$ (the Akaike information criterion, AIC, analysis provided less support for the $\Delta T$ model as the driver of masting in our population: $\Delta \mathrm{AIC}=130.5$, see Supplementary Table 1). Our analysis of temporal contributions attributed the temporal change in seed production largely to increasing temperatures (Fig. 2). Sensitivity of seed production to increasing growing season mean temperature was $0.64 \pm 0.44$ (mean \pm s.e.m.; seeds per 7-min count per tree per year for each ${ }^{\circ} \mathrm{C}$ change per year), while sensitivity to increasing summer temperature a year before seed dispersal was $1.30 \pm 0.90$ (seeds per 7-min count per tree per year for each ${ }^{\circ} \mathrm{C}$ change per year). This suggests that the increase in mean seed production was caused by two parallel mechanisms. First, warmer growing season temperatures are likely to enhance average seed output through lengthening of the growing season and increased photosynthesis $^{32}$. Second, more frequent warm summers in recent years apparently trigger large flowering events more frequently and simultaneously reduce the frequency of years with no reproduction. The resource budget model predicts that more frequent weather cueing should weaken the reinforcing dynamics of stored resources on among-tree synchrony of reproductive variation ${ }^{17,26}$ - a pattern consistent with our data. While other variables, such as summer temperature $2 \mathrm{yr}$ before seed fall or nitrogen deposition in the past $5 \mathrm{yr}$, significantly explained variance of annual seed production in our beech populations (Supplementary Table 1), they did not correlate with the temporal trends in seed production (Fig. 2).

Unfortunately for the trees, desynchronization and more regular seeding weakened the masting benefits that economies of scale provided to European beech (see Supplementary Table 2 for outputs of all models). The proportion of predispersal seed predation by Cydia sharply decreased with increasing ratio of the previous to the current year seed production (Fig. $3, z=-8.90, P<0.001$ ), indicating a strong starvation effect (numerical response) of beech masting on the moth population. The slope of that relationship did not change with time but the intercept progressively increased with time $(z=9.72, P<0.001$, Fig. 3$)$. Thus, while masting still starved insects during years of low seed production, a lesser effect on predator numbers was seen in recent years (Fig. 3). Moreover, in accordance with the predator satiation hypothesis, weaker predator starvation 


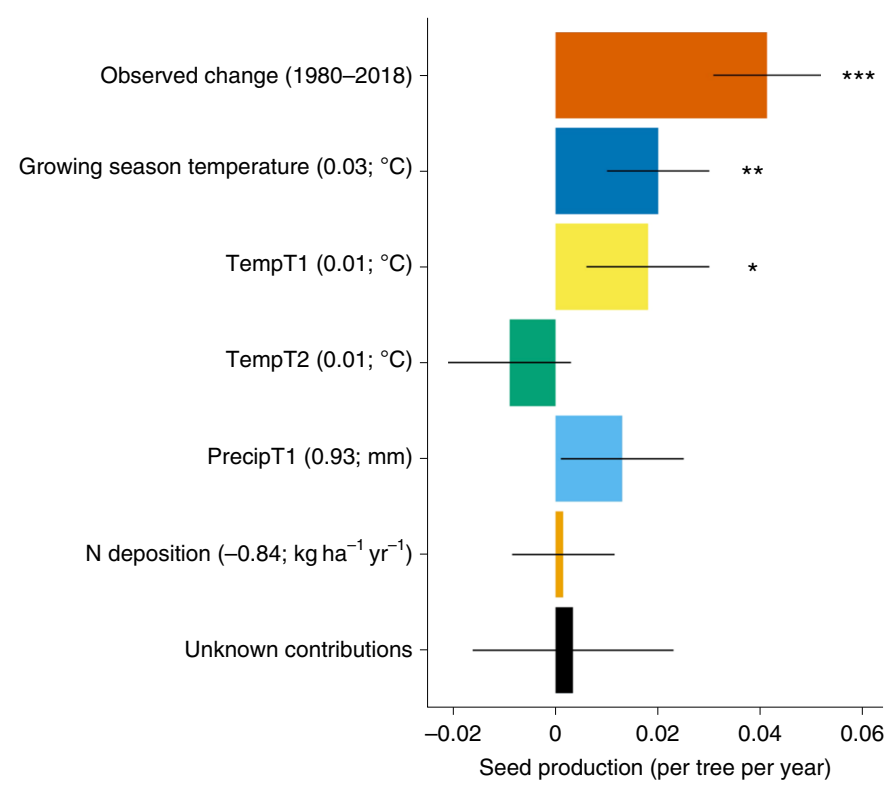

Fig. 2 | Temporal contribution of the predictor variables. The analysis, based on 12 sites and 139 trees (1980-2018), suggested that increasing temperature is the main contributor to the observed increase in European beech seed production (in seeds per tree per year per 7-min search periods). The difference between the modelled contributions and the observed trends has been considered as an unknown contribution to the temporal variation seed production. The temporal trends of the predictors are shown in brackets. Error bars for associated contributions indicate standard errors. TempT1 is the mean maximum June-July temperature in the year before seed dispersal, while TempT2 refers to $2 \mathrm{yr}$ before. PrecipT1 is summed June-July precipitation in the year before seed dispersal. See Methods for information about the methodology used to calculate the contributions. Significance levels (two-sided $t$-test): ${ }^{\star} P=0.10 ;{ }^{* \star} P=0.04$; ${ }^{\star \star \star} P<0.001$.

resulted in less effective predator satiation: the proportion of predated seeds decreased with the number of seeds produced but the slope of that relationship became less steep in recent years (interaction term seed production $\times$ year: $z=2.66, P=0.008$, Fig. 3).

In the case of pollination efficiency economy of scale, the proportion of successfully pollinated seeds increased with the summed reproductive effort of conspecifics in the population; that effect was stronger in years when the synchrony of flowering was higher (Fig. 3 and Supplementary Table 2). In the model that included both summed conspecific flowering effort and synchrony, the effect of year was not significant $(P=0.07)$. Thus, while large and synchronized reproductive effort always increased pollination efficiency, such large and synchronized flowering efforts happened less often in recent years, lowering the mean pollination efficiency (see below).

As a consequence of these weakened economies of scale, the estimated proportion of seeds predated by insects increased dramatically from $1 \%$ at the beginning of the study to over $40 \%$ in the final years (linear effect: $z=6.07, P<0.001$; quadratic effect: $z=-3.42, P<0.001$, Fig. 4). Simultaneously, the pollination efficiency decreased from $50 \%$ to $33 \%(z=-2.20, P=0.03$, Fig. 4). Thus, the large temporal increase in total seed production (Fig. 4, $\beta=0.04 \pm 0.01$ s.e.m.) became weaker once only pollinated seeds were considered $(\beta=0.03 \pm 0.01, z=4.21, P<0.001)$, and that positive trend almost disappeared for only pollinated and not-predated seeds $(\beta=0.02 \pm 0.01, z=2.22, P=0.04$, Fig. 4$)$. Overall, the increased predation pressure and decreased pollination efficiency led to 2.6-fold decrease in the probability that a female flower becomes a sound seed. This probability was estimated to equal $47 \%$
(95\% confidence interval: $31-65 \%$ ) at the beginning of the study period and decreased to $18 \%(7-36 \%)$ in the 2010s (Fig. 4). This implies that the costs to European beech per viable seed more than doubled during the last four decades as economies of scale became increasingly ineffective (Fig. 4d).

\section{Discussion}

Altered mean seed production induced by global changes has been reported in few previous studies and has found both increase ${ }^{33,34}$ and decrease ${ }^{27}$ in reproductive effort. How this translates into recruitment potential was, however, unknown since this crucially depends on parallel changes in variability and synchrony of reproduction and their consequences for seed predation and pollination efficiency ${ }^{7,13}$. Our study is the first to show that a long-term increase in mean seed production is accompanied by a decrease in synchrony and year-toyear variability of reproduction, and that these are associated with elevated costs. The apparently improved performance of European beech trees in a warmer world is offset by the breakdown of selectively beneficial strategies to avoid seed predators and improve pollination. Hence, the benefits of higher reproductive effort by the trees are largely offset by the effects of lower pollination success and higher predispersal seed predation.

The temporal decrease in variability and synchrony of seed production provides a natural experiment of how long-term changes in climate alter seed crop patterns and thereby alter the effectiveness of economies of scale. The predator satiation hypothesis consists of two parts, in which the starvation of seed predators in years of low seed production results in the satiation of reduced populations of predators in subsequent mast years ${ }^{35,36}$. More regular seeding of European beech and the reduction in the frequency of seed failures in this study weakened the starvation effect which in turn lowered the effectiveness of predispersal predator satiation. Such an effect is in line with past experimental and observational studies that found warming or nitrogen deposition was associated with increased mean seed production but also higher seed predation ${ }^{13,37}$. Furthermore, the disappearance of highly synchronized mast years in recent years reduced the efficiency of pollination and thus the proportion of successfully pollinated flowers. Together, the breakdown in economies of scale resulted in only small reproductive benefits to the studied trees, disproportionate to the size of the increase in long-term reproductive effort. Worryingly, successful beech regeneration also requires the successful starvation and satiation of postdispersal seed predators, especially small mammals ${ }^{38,39}$. Here, we show that predator satiation became less efficient in the case of a predispersal insect seed predator but if postdispersal predator satiation also became less effective, as we would predict, the net effect on surviving seeds (Fig. 4) could easily be negative overall. This is an important area for further research.

Climate warming was the major driver of decreased variability and synchrony of reproduction in European beech. Even though our statistical analyses do not directly prove causality, the results support the dominant role of increased temperatures in explaining the trends in masting pattern. First, our analysis suggested that the trend in increasing seed production is driven by warming temperatures in the preceding summer, a well-documented cue for flowering in European beech ${ }^{8,31,40}$. The resource budget models of masting $^{17,41}$ predict that more frequent occurrences of the weather cue will decrease individual variability and desynchronize flowering by weakening the reinforcing effects that resource dynamics have on reproductive synchrony ${ }^{26,42}$, which jointly decrease populationlevel seed production variability. This mechanism is supported empirically in European beech, as we found that increased mean seed production is associated both with significantly lower CVi and with lower synchrony $(\mathrm{Si})$. Second, the important effect on mean seed production of increasing mean temperatures during growing seasons supports the environmental stress hypothesis that predicts 

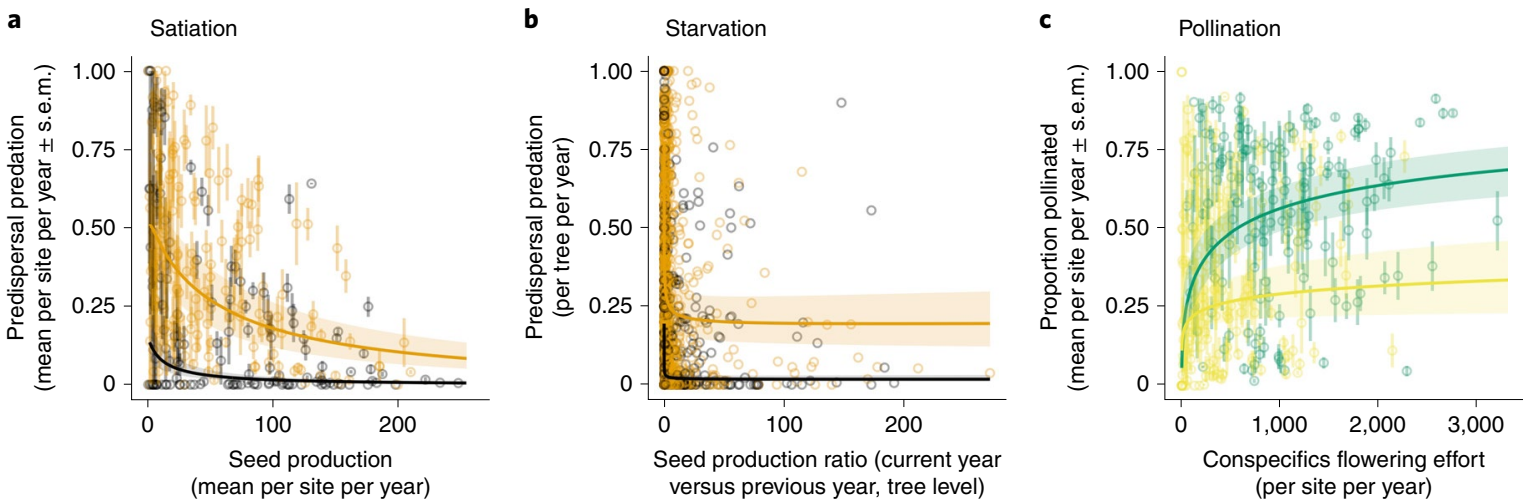

Fig. 3 | Weakening benefits to European beech from mast seeding. a,b, The proportion of seed production of each tree infested by Cydia sp. moths versus the current seed production per tree (a) and the ratio of seed production in the current versus the previous year (b). Different coloured lines show predictions for early (before 2000, black) and late (after 2000, yellow) monitoring periods. In later years, predation was higher for a given level of seed crop variation. c, The proportion of successfully pollinated seeds on a plant versus the summed reproductive effort of all other conspecific trees at a particular study site. Different coloured lines show estimates for low ( CV $>0.5$, yellow) and high $(C V<0.5$, green) within-site synchrony of flowering. When sites were more highly synchronous, pollination increased for a given flowering effort. Synchrony was calculated as CV of within-site amongtree flowering effort (thus, smaller values indicate higher among-tree synchrony of seeding). The lines are based on the significant binomial GLMMs predictions, while shading indicates the $95 \%$ confidence intervals and is based on a 39-yr dataset of 139 beech trees spaced across 12 sites in England. All models included the interaction term between the predictor showed at the $x$ axis and year. In the case of pollination efficiency, once synchrony and flowering effort were included, year effect became not significant (see Supplementary Table 2).

— All seeds —Pollinated —Pollinated and sound

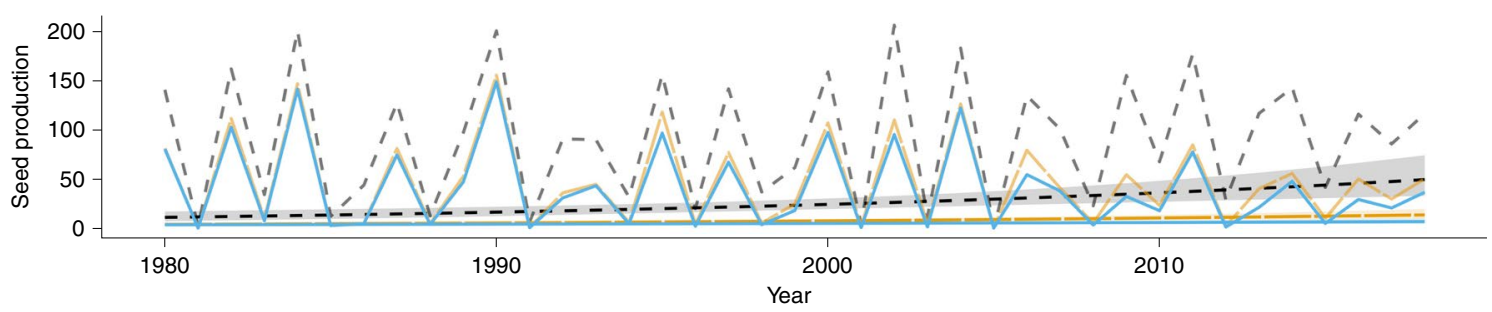

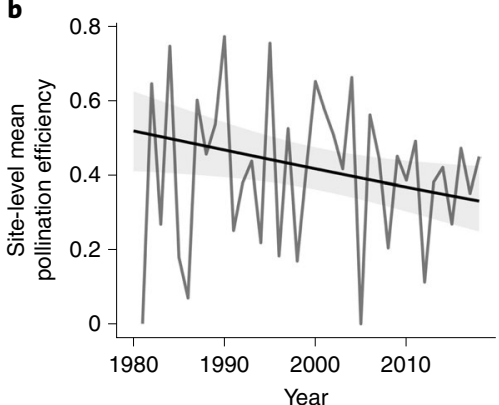

c

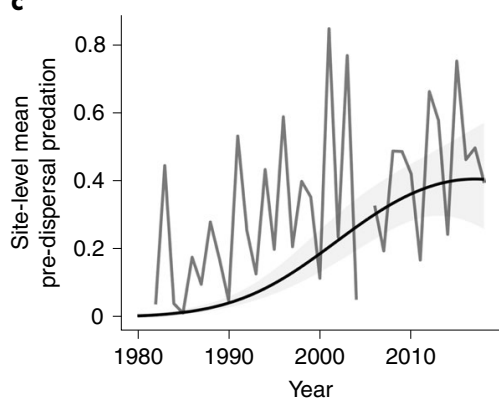

d

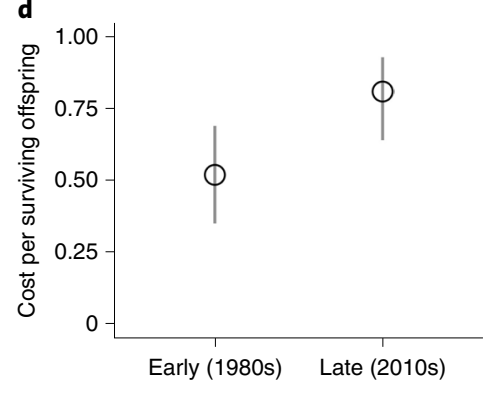

Fig. 4 | Temporal trends in European beech total and effective seed production. a-d, Temporal trends in European beech total and effective seed production (a), pollination efficiency (b), seed predation (c) and economies of scale (d), for 12 sites and 139 trees (1980-2018). Units for seed production are seeds per year per 7-min search periods. The grey dashed line indicates observed total seed production. Trends were calculated using GLMMs, with the site and trees as random intercepts and year as a fixed effect. Models also used an first-order autocorrelation structure. Shading indicates the $95 \%$ confidence intervals of the means. In a, temporal trend was calculated on the basis of either all seeds produced, only the fraction of pollinated seeds, or only pollinated and not-predated seeds. See Methods for further details. Means and $95 \%$ confidence intervals are shown in d.

masting plants will produce on average more seeds with lower variability when resource availability is high ${ }^{10,25,27}$. According to this hypothesis, plants growing under favourable conditions will be able to more rapidly accumulate the resources required for reproduction and, therefore, present a more regular pattern in seed production-a pattern consistent with the lower CVi in our data. The environmental stress hypothesis does not explicitly predict the effect of resource augmentation on reproductive synchrony. Nevertheless, warmer growing season temperatures and associated increases in resource availability potentially make resources less limiting for reproduction, weakening the positive effect of plant internal resource dynamics on synchronizing masting ${ }^{17,26,43}$. 
The changes in masting patterns reported in this study will have profound implications for the long-term future of European beech. In northern Europe where beech is predicted to expand northwards under climate warming ${ }^{44}$, our results hint that a breakdown in masting might result in recruitment limitation. This emphasizes the importance of including realistic reproduction processes within forest model $\mathrm{s}^{45}$. Similar processes may explain observed declines in beech recruitment elsewhere in Europe ${ }^{46,47}$. More generally, our results imply potential climate-driven changes in the dynamics of beech-dominated ecosystems, including the spread of Lyme disease and hantavirus by rodents dependent on beech seeds ${ }^{48-50}$, habitat selection of ground-nesting birds $\mathrm{s}^{51}$ and population dynamics of small mammal predators ${ }^{52}$. Similar changes are likely to occur in other masting species, with other negative conservation consequences $^{53}$, but such long-term datasets as the one reported here are extremely rare ${ }^{27}$. Thus, experiments to better understand the mechanisms underlying masting, and consequently better predict the consequences of a changing climate for plant reproductive patterns and global vegetation dynamics, should become a research priority $^{54}$. The net benefits of climate warming in the European beech system studied here accrue largely to an invertebrate seed predator, which suggests that ecological interactions may determine the realworld consequences of global change.

\section{Methods}

Study species. European beech (F. sylvatica L.) is a major forest-forming species in temperate Europe. The seeds are eaten and dispersed by a suite of vertebrates ${ }^{37,39}$ and destroyed by a seed-eating moth, C. fagiglandana Z. (Tortricidae). Because fruit and seed coats develop if pollination occurs and unpollinated fruits lack a seed (kernel $)^{55}$, relatively accurate estimates of pollination can be made from seed production data. European beech produces flowers in the spring, which are fertilized and develop into mature fruit in the same year as they were pollinated. Flower induction happens in the summer before the flowering year.

Data collection. We sampled seed production in 139 beech trees located at 12 sites spaced across England annually for 39 yr (1980-2018) (Supplementary Fig. 1). The ground below each tree was searched for seeds for $7 \mathrm{~min}$ and seeds were later classified as sound, or empty with formed pericarps (not pollinated), or damaged by Cydia sp. moth. Detailed descriptions of sites and procedures are given in refs. ${ }^{55,56}$.

Nitrogen deposition data for each site were estimated using the FRAME model (Fine Resolution Atmospheric Multipollutant Exchange ${ }^{57}$ ), an atmospheric chemistry and transport model, to produce estimates of $\mathrm{N}$ deposition ${ }^{58}$. Deposition data were available at a $5 \times 5 \mathrm{~km}^{2}$ resolution and produced estimates of both total reduced and oxidized $\mathrm{N}\left(\mathrm{kg} \mathrm{Nha}^{-1} \mathrm{yr}^{-1}\right)$ over deciduous forest for three snapshots (1970, 1990 and 2010). Linear interpolation was used to estimate annual deposition. Mean monthly maximum temperature and monthly sum precipitation for each site were obtained from the corresponding $0.25^{\circ}$ grid cell of the E-OBS dataset (v.19.0e $)^{59}$.

Analysis. Trends in seed production. We started our analysis by asking whether and how seed production patterns of European beech changed over the last 39 years. We built a zero-inflated, negative binomial family generalized linear mixed model (GLMM) with first-order autocorrelation structure, and included total yearly seed production per tree as a response while year was included as fixed effect in both in count and logit part of the model. The model included tree ID and site as random intercepts.

Temporal contributions and sensitivities of changes. To attribute the temporal trends in seed production to its possible drivers, we used the temporal contribution method $^{60,61}$. First, using the tree ID and site as the random intercepts and an firstorder autocorrelation structure, we modelled seed production as a function of weather cues identified as important for beech seeding in past studies ${ }^{62,63}$; that is, mean maximum temperature and summed precipitation in summer (June and July) 1 and 2 yr before seed dispersal. We also included mean temperature in the growing season (May-August) and nitrogen deposition-that is, the cumulative totals of the previous $5 \mathrm{yr}$ to test whether resource augmentation drives the trend. We then used the full model to predict the change of the response variables during the study period (1980-2018). We first calculated the observed trend (slope estimate \pm standard error of the slope estimate) in our data using GLMMs with random intercepts and temporal autocorrelation structure (see Trends in seed production). We then calculated the trend predicted by the full model and the trends predicted by the same model but maintaining the predictors constant one at a time (for example, summer temperature is held constant, using the median values per site, while all other predictors change according to the observations). The difference between the observed trend and when one variable was controlled was the contribution of that predictor variable to the change in the response variable. The difference between all individual contributions and the observed trend were considered to be unknown contributions. Finally, we calculated the average seed production sensitivities to predictor changes by dividing the temporal contributions by the trends of the predictor variables. All errors were calculated using the error-propagation method ${ }^{60}$.

Changes in masting behaviour (time series). To explore whether changes in mean seed production were accompanied by changes in annual variation and amongplant synchrony in reproduction we calculated variability and synchrony on a 10-yr sliding window with 1-yr step size from 1980 to 2018 for each tree (for plant-level analysis) or site (for site-level analysis) separately. We used the CV as a measure of temporal variability and the mean Pearson cross-correlation as a measure of reproductive synchrony. $\mathrm{CV}$ was calculated both at $\mathrm{CVi}$ and $\mathrm{CVp}^{30}$. Similarly, synchrony was calculated as a mean pairwise correlation of seed production of an individual plant with all other individuals observed at the site (within-site synchrony, $\mathrm{Si}$ ) or as a mean pairwise correlation of mean site-level seed production with all other sites (among-populations synchrony, Sp). Next, these rolling masting metrics were included as a response in linear mixed models with first-order autocorrelation structure and tree ID and site (for CVi and $\mathrm{Si}$ ) or only site (CVp and $\mathrm{Sp}$ ) included as random intercepts.

Economies of scale. We explored whether beech masting provides fitness benefit through economies of scale and whether that benefit changed with time. To do so, we built three binomial family GLMMs: two with proportion of seeds predated (predator satiation economy of scale) and another with proportion of seeds pollinated (pollination efficiency economy of scale) included as a response, all per tree per year. In all models, we used tree ID and site as random intercepts, observation-level random effect to account for overdispersion and first-order autocorrelation structure. In the first predator satiation model, the fixed effect included tree-level yearly seed production (satiation effect or functional response of the predator), while in the second, the fixed effect included the ratio of the number of seeds produced in the current year to the number produced in the previous year (starvation effect or the numerical response of the predator). In the pollination efficiency model, fixed effects included summed number of total seeds produced by all conspecific trees at a particular site, the within-site within-year synchrony of seeding (calculated as coefficient of variation) and their interaction term. In all models, we also included the quadratic terms of fixed effects which were retained or dropped on the basis of the standard AIC criteria ${ }^{64}$. Finally, to test for temporal patterns in economies of scale we included the second-order interactions of the above-listed fixed factors with year. These were removed from the final models if not significant.

Temporal changes in pollinated and unpredated seeds, and costs of reproduction. In the final step, we explored how the proportion of pollinated and predated seeds changed over time, how this translated into the production of 'pollinated' and 'pollinated and not-predated' seeds, and how all these affected beech reproductive costs. The temporal change in proportion of predated and pollinated seeds was tested using binomial GLMMs with similar structure as in tests of economies of scale but using year as a fixed factor. In the case of proportion of predated seeds, we also included the previous year seed production as a covariate as this strongly affects Cydia population dynamics (see Results). In turn, temporal change in the production of 'pollinated' and 'pollinated and not-predated' seeds was modelled similarly as in the models exploring temporal changes in total seed production but we used tree-level number of pollinated or pollinated and not-predated seeds as a response. The change in reproductive costs was calculated as $1-S$, where $S$ was calculated as probability that a seed is pollinated times probability that it will avoid Cydia predation. We used parameter estimates from the above-described GLMMs and obtained standard errors with parametric bootstrapping - that is, sampling from the distributions defined by the mean and standard error of each coefficient to obtain a joint distribution for the derived variables.

All statistics were run in R (v.3.4.1), mixed models were fitted via glmmTMB ${ }^{65}$. Model validation was run with the DHARMa package ${ }^{66}$. We used the windowscanr package for rolling window analysis ${ }^{67}$. In models in which we detected heteroscedasticity of residuals, the dispersion was modelled as a function of fixed factors using the dispformula function.

Reporting Summary. Further information on research design is available in the Nature Research Reporting Summary linked to this article.

\section{Data availability}

The data that support the findings of this study are available on request from the corresponding author.

Received: 4 September 2019; Accepted: 28 December 2019; Published online: 10 February 2020 


\section{References}

1. Seidl, R. et al. Forest disturbances under climate change. Nat. Clim. Change 7, 395-402 (2017).

2. Zohner, C. M., Mo, L. \& Renner, S. S. Global warming reduces leaf-out and flowering synchrony among individuals. eLife 7, e40214 (2018).

3. Bastin, J.-F. et al. The global tree restoration potential. Science 365 , 76-79 (2019).

4. Luo, Y., McIntire, E. J. B., Boisvenue, C., Nikiema, P. P. \& Chen, H. Y. H. Climatic change only stimulated growth for trees under weak competition in central boreal forests. J. Ecol. 108, 36-46 (2019).

5. Angert, A. L. et al. Do species' traits predict recent shifts at expanding range edges? Ecol. Lett. 14, 677-689 (2011).

6. Koenig, W. D. et al. Is the relationship between mast-seeding and weather in oaks related to their life-history or phylogeny? Ecology 97, 2603-2615 (2016).

7. McKone, M. J., Kelly, D. \& Lee, W. G. Effect of climate change on mastseeding species: frequency of mass flowering and escape from specialist insect seed predators. Glob. Change Biol. 4, 591-596 (1998).

8. Vacchiano, G. et al. Spatial patterns and broad-scale weather cues of beech mast seeding in Europe. New Phytol. 215, 595-608 (2017).

9. Kelly, D. The evolutionary ecology of mast seeding. Trends Ecol. Evol. 9 , 465-470 (1994).

10. Fernández-Martínez, M., Vicca, S., Janssens, I. A., Espelta, J. M. \& Peñuelas, J. The role of nutrients, productivity and climate in determining tree fruit production in European forests. New Phytol. 213, 669-679 (2017).

11. Monks, A., Monks, J. M. \& Tanentzap, A. J. Resource limitation underlying multiple masting models makes mast seeding sensitive to future climate change. New Phytol. 210, 419-430 (2016).

12. Pearse, I. S., Koenig, W. D. \& Kelly, D. Mechanisms of mast seeding: resources, weather, cues, and selection. New Phytol. 212, 546-562 (2016).

13. Bogdziewicz, M., Crone, E. E., Steele, M. A. \& Zwolak, R. Effects of nitrogen deposition on reproduction in a masting tree: benefits of higher seed production are trumped by negative biotic interactions. J. Ecol. 105, 310-320 (2017).

14. Kelly, D. et al. Of mast and mean: differential-temperature cue makes mast seeding insensitive to climate change. Ecol. Lett. 16, 90-98 (2013).

15. Koenig, W. D., Knops, J. M., Carmen, W. J. \& Pearse, I. S. What drives masting? The phenological synchrony hypothesis. Ecology 96, 184-192 (2015).

16. Kelly, D., Hart, D. E. \& Allen, R. B. Evaluating the wind pollination benefits of mast seeding. Ecology 82, 117-126 (2001).

17. Rees, M., Kelly, D. \& Bjørnstad, O. N. Snow tussocks, chaos, and the evolution of mast seeding. Am. Nat. 160, 44-59 (2002).

18. Tachiki, Y. \& Iwasa, Y. Both seedling banks and specialist seed predators promote the evolution of synchronized and intermittent reproduction (masting) in trees. J. Ecol. 98, 1398-1408 (2010).

19. Norton, D. A. \& Kelly, D. Mast seeding over 33 years by Dacrydium cupressinum Lamb. (rimu) (Podocarpaceae) in New Zealand: the importance of economies of scale. Funct. Ecol. 2, 399-408 (1988).

20. Rapp, J. M., McIntire, E. J. \& Crone, E. E. Sex allocation, pollen limitation and masting in whitebark pine. J. Ecol. 101, 1345-1352 (2013).

21. Moreira, X., Abdala-Roberts, L., Linhart, Y. B. \& Mooney, K. A. Masting promotes individual- and population-level reproduction by increasing pollination efficiency. Ecology 95, 801-807 (2014).

22. Linhart, Y. B., Moreira, X., Snyder, M. A. \& Mooney, K. A. Variability in seed cone production and functional response of seed predators to seed cone availability: support for the predator satiation hypothesis. J. Ecol. 102, 576-583 (2014).

23. Kelly, D. et al. Predator satiation and extreme mast seeding in 11 species of Chionochloa (Poaceae). Oikos 90, 477-488 (2000).

24. Espelta, J. M., Cortés, P., Molowny-Horas, R., Sánchez-Humanes, B. \& Retana, J. Masting mediated by summer drought reduces acorn predation in Mediterranean oak forests. Ecology 89, 805-817 (2008).

25. Kelly, D. \& Sork, V. L. Mast seeding in perennial plants: why, how, where? Annu. Rev. Ecol. Syst. 33, 427-447 (2002).

26. Bogdziewicz, M., Steele, M. A., Marino, S. \& Crone, E. E. Correlated seed failure as an environmental veto to synchronize reproduction of masting plants. New Phytol. 219, 98-108 (2018).

27. Pearse, I. S., LaMontagne, J. M. \& Koenig, W. D. Inter-annual variation in seed production has increased over time (1900-2014). Proc. R. Soc. B 284 , 20171666 (2017).

28. Walther, G.-R. et al. Ecological responses to recent climate change. Nature 416, 389-395 (2002).

29. Chen, I.-C., Hill, J. K., Ohlemüller, R., Roy, D. B. \& Thomas, C. D. Rapid range shifts of species associated with high levels of climate warming. Science 333, 1024-1026 (2011)

30. Koenig, W. D. et al. Dissecting components of population-level variation in seed production and the evolution of masting behavior. Oikos 102, 581-591 (2003).
31. Bogdziewicz, M. et al. Masting in wind-pollinated trees: system-specific roles of weather and pollination dynamics in driving seed production. Ecology 98, 2615-2625 (2017).

32. Peñuelas, J. \& Filella, I. Responses to a warming world. Science 294, 793-795 (2001).

33. Richardson, S. J. et al. Climate and net carbon availability determine temporal patterns of seed production by Nothofagus. Ecology 86, 972-981 (2005)

34. Buechling, A., Martin, P. H., Canham, C. D., Shepperd, W. D. \& Battaglia, M. A. Climate drivers of seed production in Picea engelmannii and response to warming temperatures in the southern Rocky Mountains. J. Ecol. 104, 1051-1062 (2016).

35. Satake, A. \& Bjørnstad, O. N. Spatial dynamics of specialist seed predators on synchronized and intermittent seed production of host plants. Am. Nat. 163, 591-605 (2004).

36. Bogdziewicz, M., Shealyn, M., Bonal, R., Zwolak, R. \& Steele, M. A. Rapid aggregative and reproductive responses of weevils to masting of North American oaks counteract predator satiation. Ecology 99, 2575-2582 (2018).

37. Verheyen, K. et al. Juniperus communis: victim of the combined action of climate warming and nitrogen deposition? Plant Biol. 11, 49-59 (2009).

38. Zwolak, R., Bogdziewicz, M., Wróbel, A. \& Crone, E. E. Advantages of masting in European beech: timing of granivore satiation and benefits of seed caching support the predator dispersal hypothesis. Oecologia 180, 749-758 (2016)

39. Jensen, T. S. Seed-seed predator interactions of European beech, Fagus silvatica and forest rodents, Clethrionomys glareolus and Apodemus flavicollis. Oikos 44, 149-156 (1985).

40. Piovesan, G. \& Adams, J. M. Masting behaviour in beech: linking reproduction and climatic variation. Can. J. Bot. 79, 1039-1047 (2001).

41. Satake, A. \& Iwasa, Y. O. H. Pollen coupling of forest trees: forming synchronized and periodic reproduction out of chaos. J. Theor. Biol. 203, 63-84 (2000).

42. Crone, E. E. \& Rapp, J. M. Resource depletion, pollen coupling, and the ecology of mast seeding. Ann. NY Acad. Sci. 1322, 21-34 (2014).

43. Satake, A. \& Bjørnstad, O. N. A resource budget model to explain intraspecific variation in mast reproductive dynamics. Ecol. Res. 23 3-10 (2008).

44. Sykes, M. T., Prentice, I. C. \& Cramer, W. A bioclimatic model for the potential distributions of north European tree species under present and future climates. J. Biogeogr. 23, 203-233 (1996).

45. Vacchiano, G. et al. Reproducing reproduction: how to simulate mast seeding in forest models. Ecol. Modell. 376, 40-53 (2018).

46. Penuelas, J. \& Boada A global change-induced biome shift in the Montseny mountains (NE Spain). Glob. Change Biol. 9, 131-140 (2003).

47. Jump, A. S., Hunt, J. M. \& Penuelas, J. Climate relationships of growth and establishment across the altitudinal range of Fagus sylvatica in the Montseny Mountains, northeast Spain. Ecoscience 14, 507-518 (2007).

48. Clement, J. et al. Relating increasing hantavirus incidences to the changing climate: the mast connection. Int. J. Health Geogr. 8, 1 (2009).

49. Bogdziewicz, M., Zwolak, R. \& Crone, E. E. How do vertebrates respond to mast seeding? Oikos 125, 300-307 (2016).

50. Ostfeld, R. S. \& Keesing, F. Pulsed resources and community dynamics of consumers in terrstrial ecosystems. Trends Ecol. Evol. 15, 232-237 (2000).

51. Szymkowiak, J. \& Thomson, R. L. Nest predator avoidance during habitat selection of a songbird varies with mast peaks and troughs. Behav. Ecol. Sociobiol. 73, 91 (2019).

52. Schmidt, K. A. \& Ostfeld, R. S. Numerical and behavioral effects within a pulse-driven system: consequences for shared prey. Ecology 89, 635-646 (2008).

53. Elliott, G. \& Kemp, J. Large-scale pest control in New Zealand beech forests. Ecol. Manag. Restor. 17, 200-209 (2016).

54. Bogdziewicz, M. et al. From theory to experiments for testing the proximate mechanisms of mast seeding: an agenda for an experimental ecology. Ecol. Lett. 23, 210-220 (2020).

55. Nilsson, S. G. \& Wastljung, U. Seed predation and cross-pollination in mast-seeding beech (Fagus sylvatica) patches. Ecology 68, 260-265 (1987).

56. Packham, J. R., Thomas, P. A., Lageard, J. G. A. \& Hilton, G. M. The English beech masting survey 1980-2007: variation in the fruiting of the common beech (Fagus sylvatica L.) and its effects on woodland ecosystems. Arboric. J. 31, 189-214 (2008).

57. Dore, A. J. et al. The influence of model grid resolution on estimation of national scale nitrogen deposition and exceedance of critical loads. Biogeosciences 9, 1597-1609 (2012).

58. Tipping, E. et al. Long-term increases in soil carbon due to ecosystem fertilization by atmospheric nitrogen deposition demonstrated by regionalscale modelling and observations. Sci. Rep. 7, 1-11 (2017).

59. Cornes, R. C., van der Schrier, G., van den Besselaar, E. J. \& Jones, P. D. An ensemble version of the E-OBS temperature and precipitation data sets. J. Geophys. Res. Atmos. 123, 9391-9409 (2018). 
60. Fernández-Martínez, M. et al. Global trends in carbon sinks and their relationships with $\mathrm{CO}_{2}$ and temperature. Nat. Clim. Change 9, 73 (2019).

61. Fernández-Martínez, M. et al. Atmospheric deposition, $\mathrm{CO}_{2}$, and change in the land carbon sink. Sci. Rep. 7, 9632 (2017).

62. Hacket-Pain, A. J. et al. Climatically controlled reproduction drives interannual growth variability in a temperate tree species. Ecol. Lett. 21 1833-1844 (2018).

63. Drobyshev, I. et al. Masting behaviour and dendrochronology of European beech (Fagus sylvatica L.) in southern Sweden. For. Ecol. Manag. 259, 2160-2171 (2010).

64. Burnham, K. P. \& Anderson, D. R. Model Selection and Multimodel Inference: A Practical Information-Theoretic Approach (Springer, 2003).

65. Brooks, M. E. et al. glmmTMB balances speed and flexibility among packages for zero-inflated generalized linear mixed modeling. $R$ J. 9, 378-400 (2017).

66. Hartig, F. DHARMa: Residual diagnostics for hierarchical (multi-level/mixed) regression models. R package v.0.1.5 (CRAN, 2017).

67. Tavares, H. windowscanr: Apply functions using sliding windows. R package version v.0.1 (RDRR, 2019).

\section{Acknowledgements}

The study was partially funded by the UK Natural Environment Research Council grant no. NE/S007857/1. M.B. was supported by the Polish National Science Centre (grants Sonatina no. 2017/24/C/NZ8/00151 and Uwertura no. 2018/28/U/NZ8/00003). We thank M. Fernández-Martínez for statistical consultation and R. Chiverrell, A. Morse and L. McGarty for comments on the manuscript. The late J.R. Packham and G.M. Hilton are acknowledged for initiating the English Beech Masting Survey, as are friends, family and colleagues who have assisted in annual data collection. We acknowledge the E-OBS dataset from the EU-FP6 project UERRA (http://www.uerra.eu) and the data providers in the ECA\&D project (https://www.ecad.eu). We thank U. Dragosits and S. Tomlinson (NERC Centre for Ecology \& Hydrology) for providing nitrogen deposition data and advice.

\section{Author contributions}

M.B. conceived the study and drafted the manuscript. M.B. led the analysis with input from A.H.P. and D.K. P.A.T., J.G.A.L. and A.H.-P. collected and managed the data. All authors interpreted the results, revised the text and provided critical feedback, and helped shape the final text.

\section{Competing interests}

The authors declare no competing interests.

\section{Additional information}

Supplementary information is available for this paper at https://doi.org/10.1038/ s41477-020-0592-8.

Correspondence and requests for materials should be addressed to M.B.

Peer review information Nature Plants thanks Eliane Schermer and the other, anonymous, reviewers for their contribution to the peer review of this work.

Reprints and permissions information is available at www.nature.com/reprints.

Publisher's note Springer Nature remains neutral with regard to jurisdictional claims in published maps and institutional affiliations.

(c) The Author(s), under exclusive licence to Springer Nature Limited 2020 